\title{
Test and Analysis of an Inflatable Parabolic Dish Antenna
}

\author{
James L. Gaspar* \\ NASA Langley Research Center, Hampton, Virginia, 23681, USA \\ Tham Sreekantamurthy ${ }^{\dagger}$, Troy Mann ${ }^{\ddagger}$, and Vaughn Behun ${ }^{\S}$ \\ Swales Aerospace, Hampton, Virginia, 23681, USA \\ Robert R. Romanofsky ${ }^{* *}$ and Kevin Lambert ${ }^{\dagger \dagger}$ \\ NASA Glenn Research Center, Cleveland, Ohio, 44135 USA \\ James Pearson \\ SRS Technologies, Huntsville, Alabama 44135, USA
}

\begin{abstract}
NASA is developing ultra-lightweight structures technology for large communication antennas for application to space missions. With these goals in mind, SRS Technologies has been funded by NASA Glenn Research Center (GRC) to undertake the development of a subscale ultra-thin membrane inflatable antenna for deep-space applications. One of the research goals is to develop approaches for prediction of the radio frequency and structural characteristics of inflatable and rigidizable membrane antenna structures. GRC has teamed with NASA Langley Research Center (LaRC) to evaluate inflatable and rigidizable antenna concepts for potential space missions. GRC has completed tests to evaluate RF performance, while LaRC completed structural tests and analysis to evaluate the static shape and structural dynamic responses of a laboratory model of a 0.3 meter antenna. This paper presents the details of the tests and analysis completed to evaluate the radio frequency and structural characteristics of the antenna.
\end{abstract}

\section{Introduction}

$S^{\mathrm{p}}$ PACE antenna development has been driven by several important factors such as reflectivity, shape accuracy, low weight and low packaging volume (Ref. 1-7). Because of these design constraints, the demand for high performance antennas has increasingly stimulated the development of inflatable and deployable antennas due to their ability to achieve low weight and low packaging volume, and their promise of better shape accuracy (Ref. 8). The antenna shape accuracy, which is defined as the degree to which the actual shape of the structure deviates from the intended shape, is an important factor affecting the electromagnetic performance of the antenna. The shape requirement has become the most critical requirement for the development of the newer class of large ultra-thin membrane inflatable and deployable antenna structures, which are inherently very flexible and hence susceptible to shape distortions in the space operating environment.

The shape of the antenna surface originates in the structural design process, gets modified as it is adapted through the fabrication process, and obtains its final form only after it actually settles upon deployment in space. Antenna shape accuracy in space is influenced by a number of factors including: (1) the specific structural design and the type of antenna, such as umbrella type, inflatable, or petaline; (2) manufacturing state-of-the-art capabilities in metal working, moldings and fabrication of the contoured shape of the reflector; and (3) the operating

\footnotetext{
* Aerospace Engineer, NASA Langley Research Center, Hampton, Virginia, AIAA Member

${ }^{\dagger}$ Aerospace Engineer, Swales Aerospace, Hampton, Virginia, AIAA Member

‡ Aerospace Engineer, Swales Aerospace, Hampton, Virginia, AIAA Member

$\S$ Aerospace Engineer, Swales Aerospace, Hampton, Virginia, AIAA Member

** Electronics Engineer, NASA Glenn Research Center, Cleveland, Ohio, AIAA Member

${ }^{\dagger \dagger}$ Electronics Engineer, NASA Glenn Research Center, Cleveland, Ohio, AIAA Member

㧊 Aerospace Engineer, SRS Technologies, Huntsville, Alabama, AIAA Member
} 
environment and the entire antenna system response to static and vibratory excitations from dynamic and thermal loads, severe attitude control inputs, antenna shape control inputs, and impact loads from space debris.

During the development of newer antennas, many structural research studies and laboratory experiments have been performed to predict and reduce reflector surface distortions (Ref. 9-11). For gossamer structures, analytical characterizations of on-orbit shape distortions (Ref. 12-17) are important because the space environment is difficult to simulate on the ground; ground testing limitations include the difficulties of simulating support-free operation and control under extremely low structural loadings brought on by zero-gravity conditions of space, as well as the inherent difficulty that full scale gossamer antennas may not be able to withstand high loads in the ground environment. However, laboratory testing before flight is also important for verifying the geometrical shape of the fabricated antenna, providing experimental data for verification of structural analyses, and confirming operation of the inflation and deployment mechanisms on the ground, even though it constitutes a high loading environment. Recent laboratory tests of gossamer structures such as inflatable and deployable antennas and solar sails have been focused on measurement of their static and dynamic characteristics using photogrammetric techniques (Ref. 22-24). In parallel with these analytical and ground testing advances in shape prediction and measurement, the antenna manufacturers have sought improvements in the fabrication process to precisely contour the thin-membrane surfaces of the reflectors (Ref. 18-21, and Ref. 25-28). These three approaches, analytical studies, laboratory tests and fabrication techniques, by themselves or in combination, are used to ensure that the antenna design margins, antenna shape errors, and structural mass are held to acceptable limits in the development of high precision antennas.

NASA Langley Research Center (LaRC) is developing ultra-lightweight structures technology for antenna and space solar power applications for NASA missions (Ref. 17 and 29), with one of the research goals being the development of approaches for prediction of structural response characteristics of inflatable and rigidizable membrane antenna structures. As part of this goal, LaRC, in collaboration with NASA Glenn Research Center (GRC), is evaluating a subscale ultra-thin membrane inflatable antenna for deep space applications. This development program includes an immediate task to evaluate the RF performance and develop computational models for predicting the static and structural dynamic characteristics of the antenna, and a follow-on task to demonstrate test methods for measuring the static shape and structural dynamic responses on a laboratory model of an antenna. Recently, RF tests were completed at GRC and structural analysis computational studies were performed at LaRC to characterize the nonlinear static response and normal modes of the inflatable membrane reflector using a finite element model of the antenna. Subsequently, static shape and dynamic tests were also conducted at LaRC on a 0.3 meter laboratory model of the antenna in both atmospheric and vacuum conditions. This paper presents the details of the RF and structural characterization tests and the analytical advances made in the development of the finite element analysis for a 0.3 meter laboratory model of an inflatable antenna reflector.

\section{Test Measurements}

The laboratory model of the 0.3 meter reflector antenna is shown in Figure 1 . The antenna is an off-axis parabolic reflector that operates at the $8.4 \mathrm{GHz}$ NASA deep space network frequency. The antenna membranes are Kapton material of 0.7 mil thickness, and the membrane dish is inflated to a nominal internal pressure of $14 \mathrm{~Pa}$. The inflated membrane is held stretched by 32 soft elastic catenaries that are equally spaced around the circumferential edge of the dish. One end of each elastic band of the catenaries is attached to the membrane edge through a Kapton tab and the other end is attached to a rigid oval frame.

\section{A. Radio Frequency Test}

Large aperture inflatable antennas promise microwave performance similar to solid reflectors, low aerial density $(<1 \mathrm{~kg} / \mathrm{m} 2)$, and high packaging efficiency for both space and terrestrial applications. Thin polymer (CP-1) films are cast on a precisely machined mandrel, thermally cured, and released. Two such films are cast per antenna. One film is metalized with a vapor deposited aluminum coating approximately 1200 Angstrom thick. The thin films are sealed around the periphery to hold inflation pressure. Structures up to 10 meters in diameter have recently been demonstrated for RF applications and solar concentrator applications. On-axis, offset, and Cassegrain antennas are currently being designed, fabricated, and characterized. As a prelude to development of a full-scale inflatable membrane antenna, the 0.3 meter off-axis reflector was designed, fabricated and tested. 
NASA-GRC and SRS conducted RF characterization tests of two 0.3 meter aperture inflatable thin film polymer (CP-1) antennas (labeled RF2 and RF3). These antennas were tested in the NASA-GRC Far Field Facility at $8.4 \mathrm{GHz}$ (at vertical and horizontal polarizations), which is the NASA Deep Space Network frequency. The facility's far field limit is 0.3 meter at lamda/40. A total of 28 tests were conducted with internal pressures from 1.7 through $16.2 \mathrm{~Pa}$, at rotations from 0 to 360 degrees (including side lobes \& back lobes), with the catenary loads fixed. Figure 1 shows a prototype unit (RF2) with waveguide feed horn. Figure 2 shows the results comparing the RF antenna performance of the two 0.3 meter antenna test articles (RF2 \& RF3) against computer simulation. Inflation pressure during these measurements was $14.9 \mathrm{~Pa}$. The measured antenna performance is comparable to that of a conventional rigid reflector and reasonably well matched to the analytical model prediction. The center beam correlation of test and analysis was excellent. Some side lobe reduction was identified, this is likely due to the non-optimized feed horn (5dbm tested vs $11 \mathrm{dbm}$ desired) and also the antenna edge effects may have contributed too.

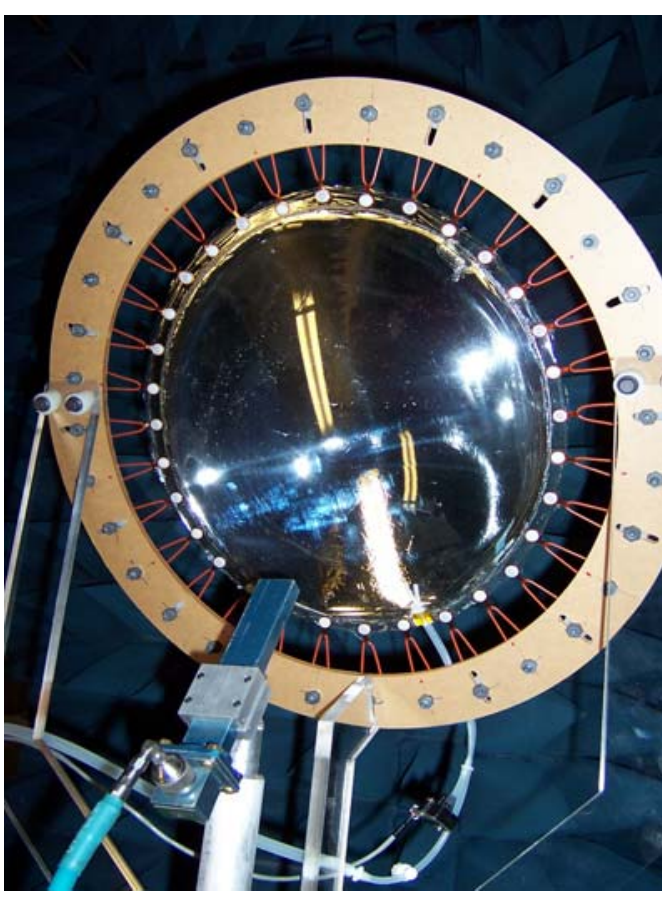

Figure 1. 0.3 meter Antenna (RF2) inside the NASA-GRC Far Field Range.

SRS 0.3 meter Inflatable Antenna

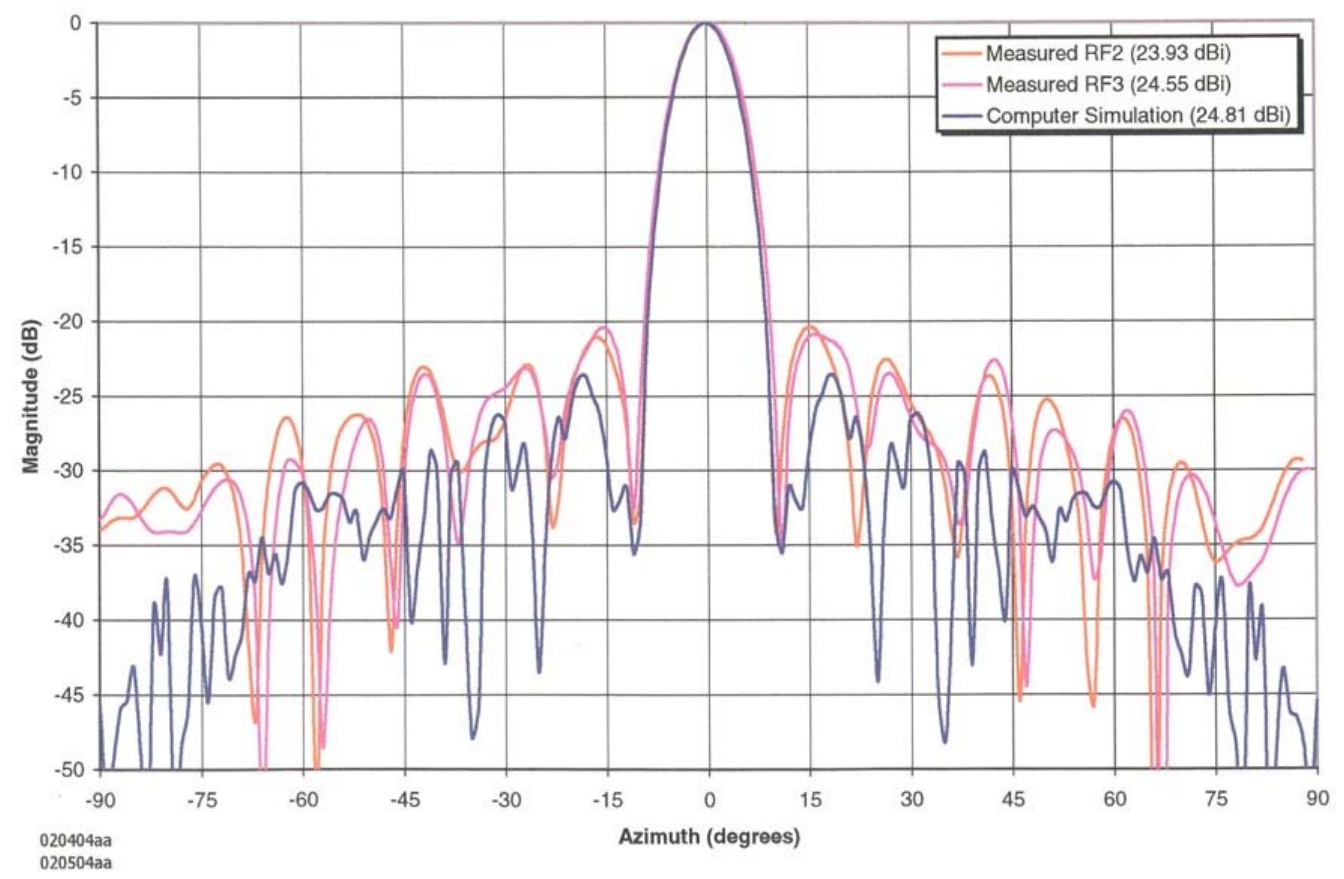

Figure 2. Measured and modeled far-field azimuthal radiation pattern of both $0.3 \mathrm{~m}$ inflatable membrane reflectors at $8.4 \mathrm{GHz}$. 
In order to reduce cost some what, and possibly reduce surface wrinkling from packaging, a "shear" metal coating was investigated. Since the reflection coefficient is governed by the impedance of the film and not related to film thickness, as long as the film is not porous, a translucent $300 \AA$ aluminum coating was evaluated. Measured results are shown in figure 3 . The directivity was within $0.25 \mathrm{~dB}$ of the conventional coating.

Comparison of Conventional and Shear Coating

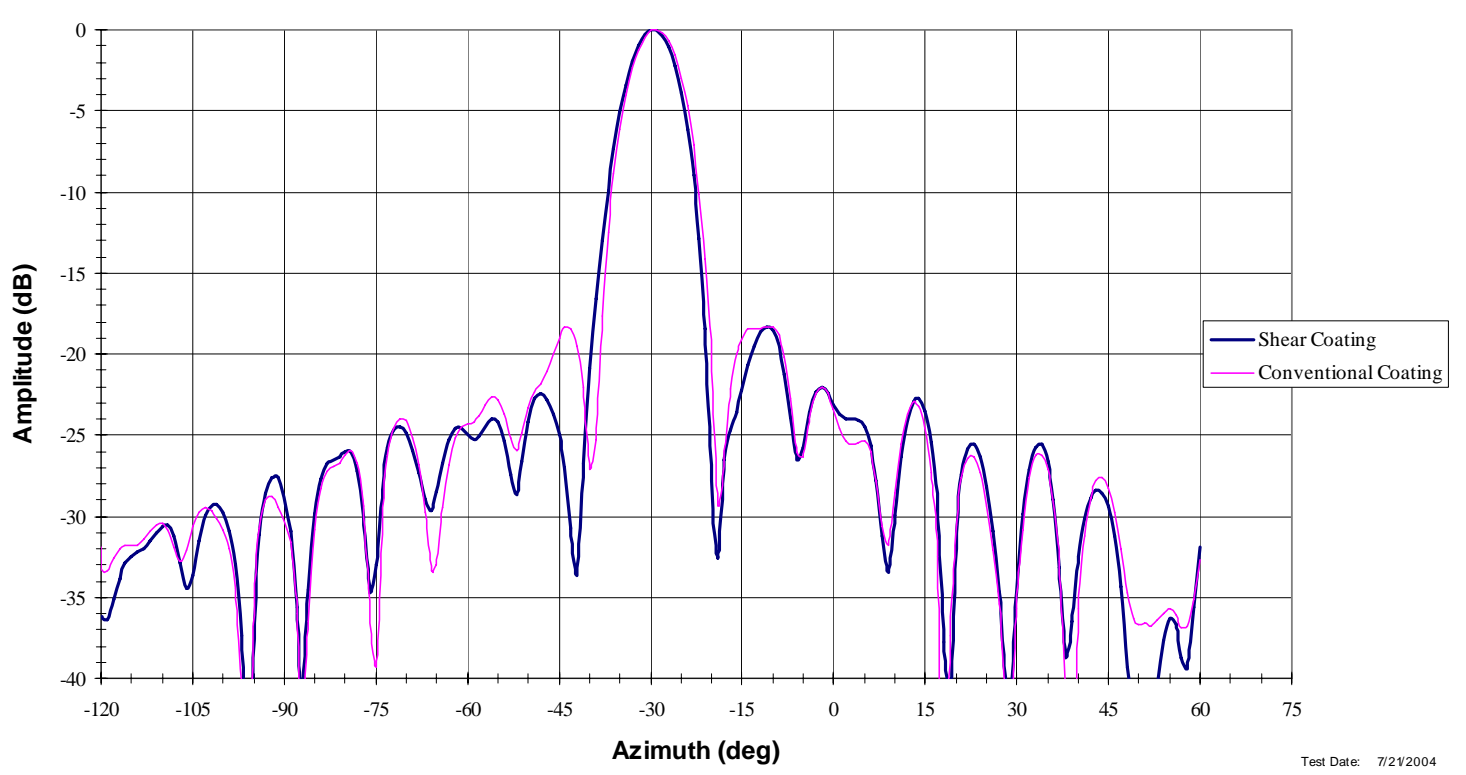

Figure 3. Conventional (1200 $\AA)$ coating versus shear $(300 \AA)$ coating.

\section{B. Static Shape Test}

Once the RF testing was completed at NASA-GRC, the antenna was shipped to NASA-LaRC for structural characterization tests. To provide measurement locations for static shape and dynamic tests, approximately 100 retro-reflective targets were placed on the reflective surface of the antenna. The retroreflective material was used to provide good signal response when illuminated with flash photography for photogrammetry or with a laser for laser Doppler vibrometry. A professional photogrammetry camera was used to precisely measure the 3-dimensional position of each of these targets when the structure was inflated to the operational pressure of $14 \mathrm{~Pa}$. Figure 4 shows the 0.3 meter antenna as equipped for the static tests.

The spatial resolution provided by the retro-reflective targets was inadequate to provide satisfactory comparison with analysis. However, the measurement did show significant differences in catenary lengths around the circumference of the antenna during the initial tests. The non-uniformity of the stress boundary condition achieved with these catenaries was not

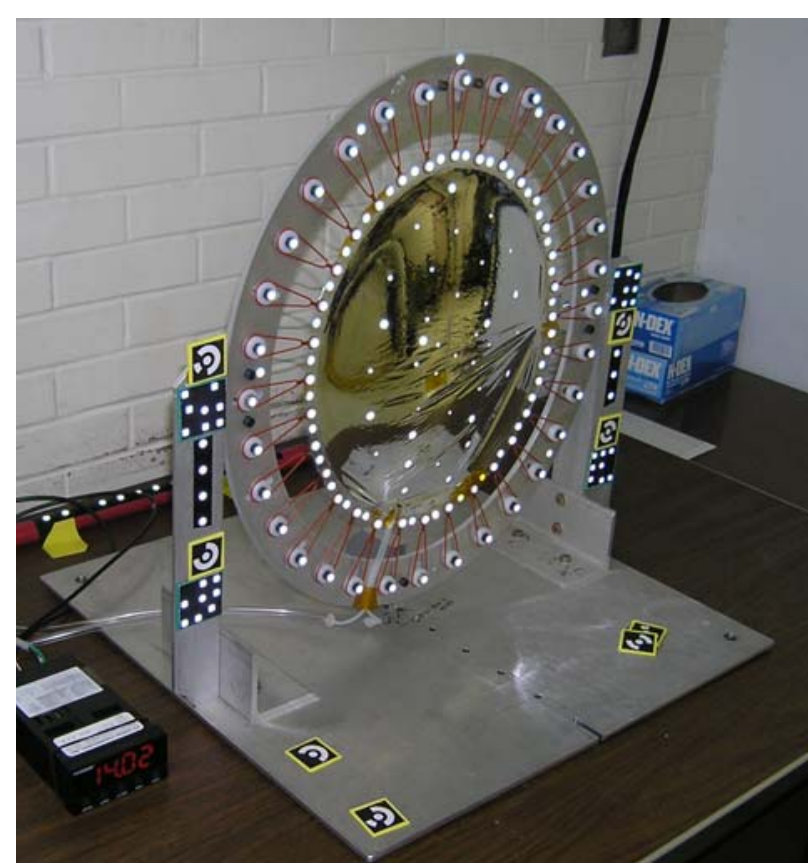

Figure 4. 0.3 meter Antenna Instrumented for Static Photogrammetry Measurements. adequate, so an attempt was made to characterize and improve the uniformity of loads in each catenary. 
First, several of the catenaries were removed from the test article and placed on a load-deflection measurement device specifically designed for measurement of the elastomers that make up the catenaries. Prescribed displacements were then applied to the elastomer and resultant loads were measured. This was repeated for several load-displacement cycles and for several catenaries. The results of these load-displacement tests were used to estimate the length of the catenary necessary to produce the stress boundary condition required by the manufacturer. Finally, the attach point of the catenary on the support frame was adjusted in an attempt to achieve this desired catenary length that would produce the nominal boundary load $(2.5 \mathrm{~N})$ for the antenna. Several iterations of this technique provided a uniform stress boundary condition that was significantly improved compared to the original setup. At this point the dynamic modal tests described in the next section were performed.

Once the dynamic tests had been completed, the test article was modified to increase the spatial resolution of the surface for static shape measurement. Initially, a target projector was used to project a large number of light points on the surface of the membrane. This allows for much greater spatial resolution while maintaining non-contact metrology techniques. Previous researchers have had some success using this technique for static and dynamic measurements of gossamer structures. However, the highly reflective convex shape of the antenna caused significant 'hot spots' in the measured images. As a result, the technique was unsuccessful at capturing the static shape at increased spatial resolution.

In order to improve the capability of the measurements while minimizing the impact on the response of the structure, a thin layer of talc powder was applied to the structure. The surface changed from a reflective to a diffuse white surface allowing for high spatial resolution static measurements of the structure with the dot projection photogrammetry technique. Figure 5 shows the structure as it was measured with the increased spatial resolution. The weight added to the structure was less than $0.5 \mathrm{~g}$. A total of 6,647 points were measured on the surface of the antenna with this technique. The spatial resolution provided significant detail in the surface height of the antenna including measurements of wrinkles of multiple sizes on the antenna. The wrinkles were due largely to repairs made to the structure during its long tenure. To reduce the wrinkles somewhat near the center of the antenna, two catenaries ( 1 at top center, 1 at bottom center) applied higher than nominal load during the shape test. Surface contours of the antenna are shown in Figure 6. Repair locations are clearly seen at the right edge and lower corner, causing radial wrinkle lines from the right edge.

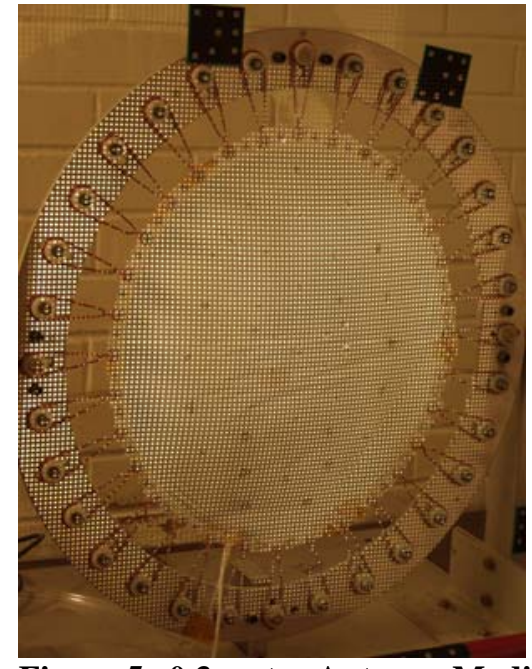

Figure 5. 0.3 meter Antenna Modified for Dot-Projection Photogrammetry.

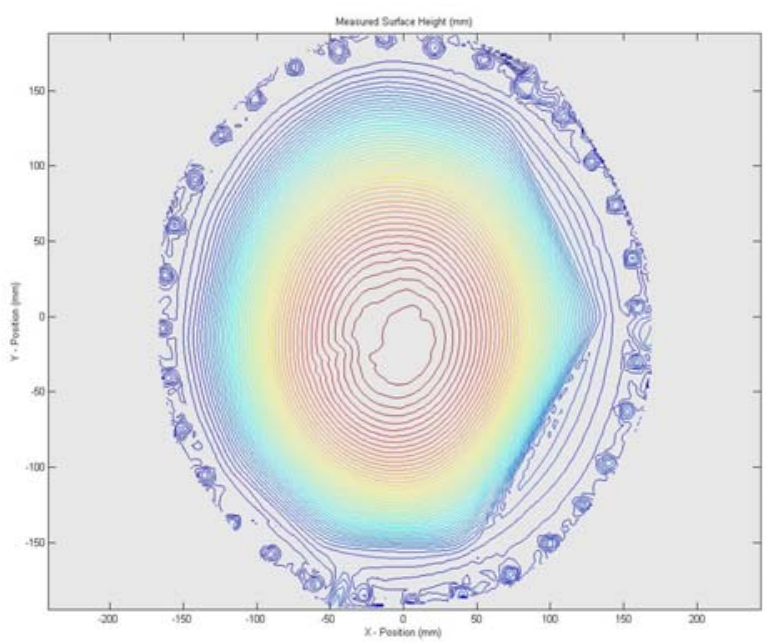

Figure 6. Surface Contours - 0.3 meter Antenna Measured with Dot-Projection Photogrammetry. 


\section{Dynamic Test}

Dynamic measurements were made of the antenna using the initial 100 retro-reflective targets with a scanning laser doppler vibrometer. The tests were completed first in ambient conditions then in vacuum at 1 torr pressure inside the NASA-Langley Structural Dynamics Branch 8-foot diameter spherical vacuum chamber. The setup and configuration for the vacuum tests is shown in Figure 7, while ambient tests were completed in a similar configuration. Laser vibrometer measurements are made through a glass port in the chamber. Initially, a $5 \mathrm{lb}$. shaker was attached to the frame supporting the structure (at the upper right corner) through a 10lb. load cell. A second set of data was acquired by exciting the antenna directly (without the use of a load cell to eliminate mass loading) through one of the catenary attachment positions (also at upper right corner). Excitation was provided in

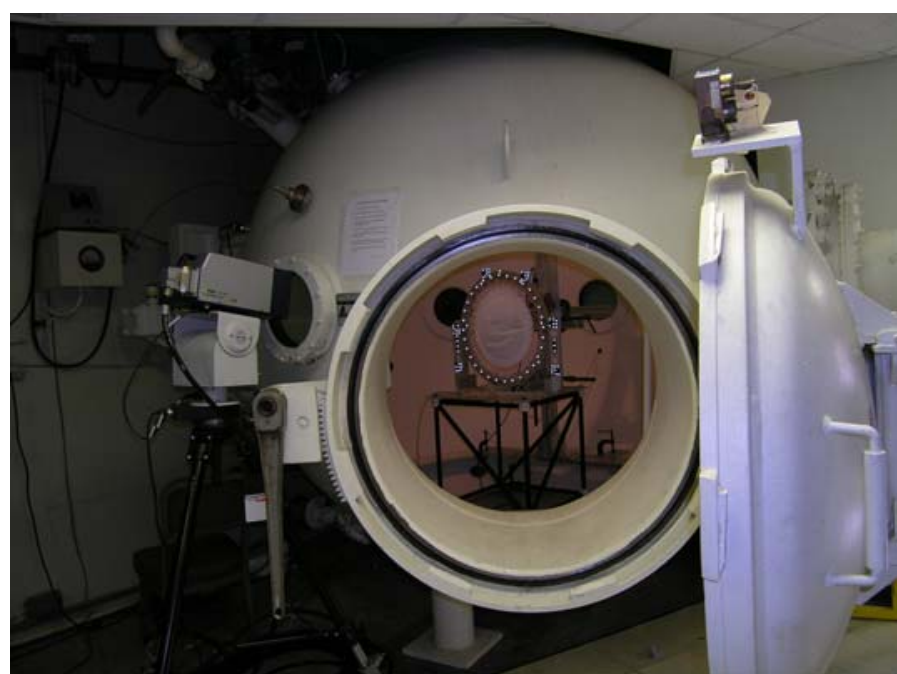

Figure 7. 0.3 meter Antenna Configuration for In-Vacuum Dynamics Measurements.

the form of a pseudo-random input from 0 to $125 \mathrm{~Hz}$ and 3 averages. The results completed in-vacuum with the excitation to the frame produced the best data. Figure 8 shows the Average Spectrum (average of all measurements) Frequency Response Function (FRF) and coherence (COH) for the in-vacuum frame excitation test. The FRF shows 10 well defined modes with good $\mathrm{COH}$ at resonance. The first two modes are essentially support frame modes (21.6, $27.5 \mathrm{~Hz}$ ) pivoting about the bolt attachment points. The next three modes are catenary flex modes with the dish undergoing rigid body motion ( $32.2 \mathrm{~Hz}$ out-of-plane, $39.2 \mathrm{~Hz}$ fore \& aft, and $40.6 \mathrm{~Hz}$ lateral). Then there is the first frame flex mode with the dish following its motion at $48.4 \mathrm{~Hz}$. The last four modes are membrane modes coupled with edge/ring motion $(53,56,61,68 \mathrm{~Hz})$. While the frequency response of the structure was repeatable, there are many questions surrounding the impact of the damaged areas and how the subsequent wrinkles may affect the dynamic response of the antenna. Further review of these test results is discussed in the test-analysis comparison section of this paper along with ODS plots for each of the modes mentioned.
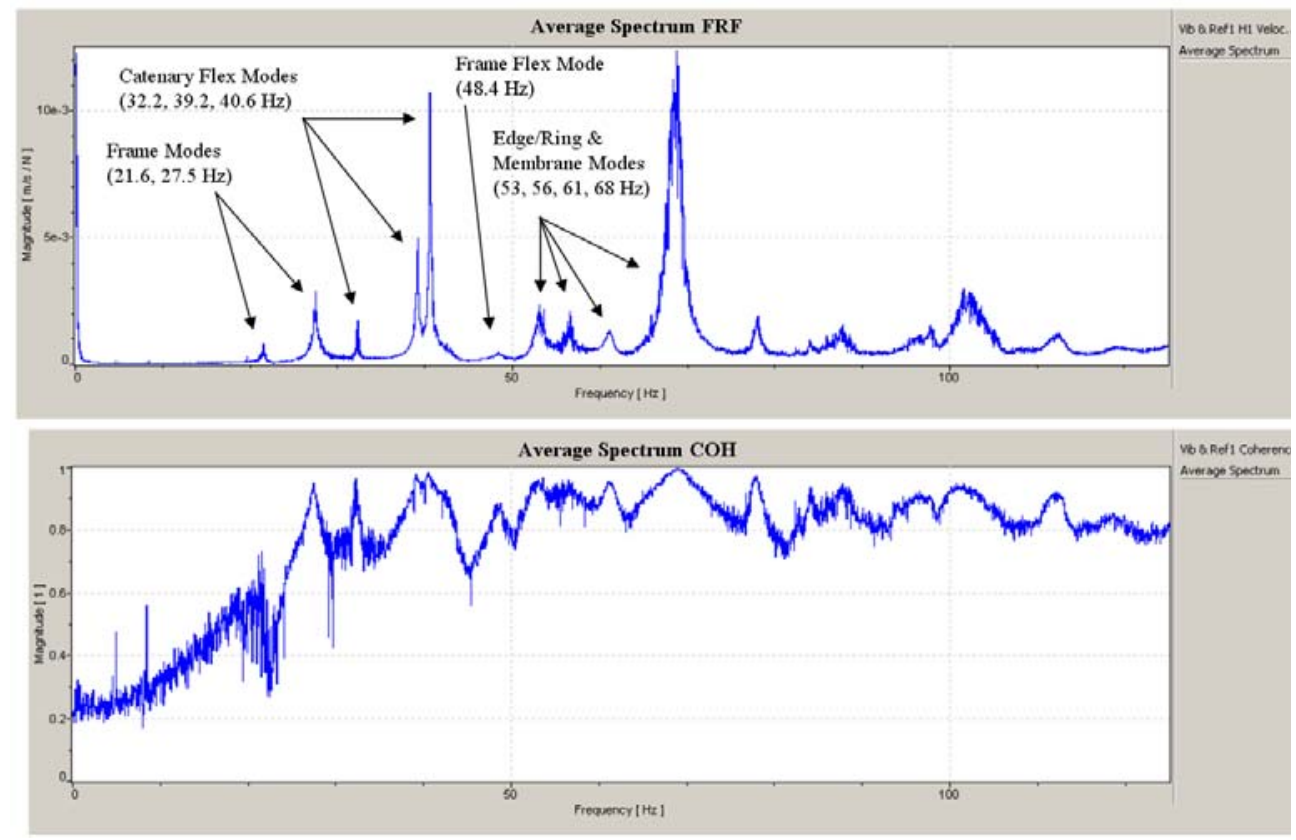

Figure 8. Average Spectrum FRF and Coherence from Dynamics Test. 


\section{Structural Analysis}

\section{A. Finite Element Model}

A finite element model was developed for the structural analysis of the off-axis parabolic reflector membrane dish antenna (Figure 9). The antenna reflector dish consists of two parabolic shell segments molded at the outer edge of the reflector to form an inflatable dish. The catenaries hold the reflector membrane in tension against the surrounding oval frame. The top and bottom membrane of the reflector dish are modeled with four-noded-quadrilateral membrane elements. The outer strip of the reflector membrane, which is elliptical shaped, was modeled using quadrilateral shell elements. The frame is modeled with triangular shell elements. Catenaries were modeled with a set of beam elements with temperature dependent material properties, so that desired prestress loads in the catenaries can be generated by suitable selection of temperature loads. The finite element model has a total of 11704 elements and 10741 nodes. The aluminum oval frame is supported at three points, at which it is fixed to the ground. The reflector dish is inflated to an internal pressure load, and also subjected to gravity load to

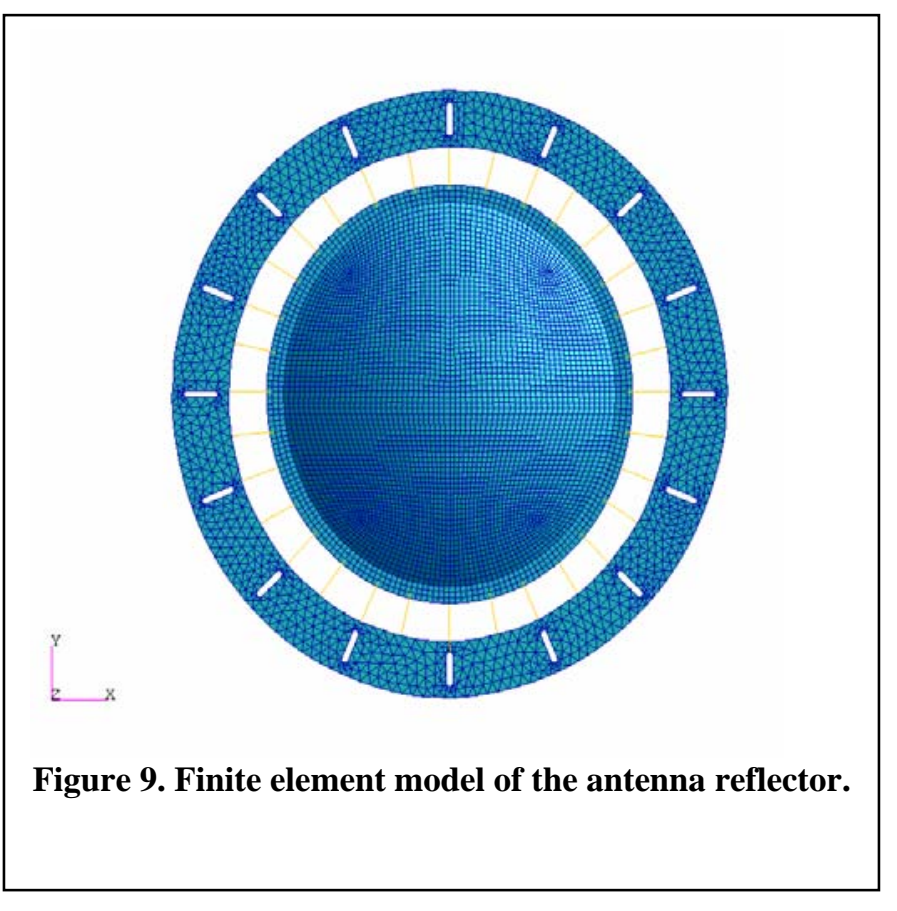
simulate the test conditions.

The static nonlinear finite element analysis of the parabolic reflector structure is performed with solution sequence 106 of the MSC/NASTRAN program, which solves a linear system of equations of incremental displacements. Normal mode vibration analysis is performed at the last converged nonlinear static analysis iteration, to determine the natural frequencies and mode shapes of the antenna structure.

\section{B. Nonlinear Static Analysis}

\section{Deformed Reflector Shape with Increasing Pre-Tension in the Catenaries}

A nonlinear static computational analysis of the antenna was performed to simulate the ground test condition of the reflector dish structure suspended from the catenaries attached to the frame. The static analysis of the antenna was carried out to estimate the deformation patterns and internal forces in the membrane of the reflector dish. The structural analysis assumed the following conditions - an internal pressure of $17.4 \mathrm{~Pa}$, 1g gravity load normal to dish, and catenary pretension loads up to $2.3 \mathrm{~N}$. In the analysis, the pretension loads in the catenaries around the elliptical edge of the reflector were increased uniformally to study the change in reflector shape deformation with increasing catenary load. The resulting deformations are computed with respect to the un-deformed original parabolic surface of the dish, and are plotted in a fringe pattern on the front surface of the dish. Figure 10 shows how the internal displacement in the membrane changes with increasing pretension in the catenaries. Among the various fringe plots shown in Figure 10, the first plot is for pretension load of $0.47 \mathrm{~N}$, where a nearly regular band of fringe shows up on the surface deformation plot. This regular fringe band is a result of the membrane undergoing rigid body motion. For small incremental pretension loads up to $0.47 \mathrm{~N}$, the inflated dish is simply getting pulled up against the gravity load, and hence the surface mostly undergoes large rigid body motion. At a pretension loads of $0.70 \mathrm{~N}$ and higher, the reflector membrane undergoes static deformations under the load, and this is indicated by a non-uniform fringe band. These deformations can be visually observed by the changes in the red and orange areas of the fringe pattern, as membrane surface changes under application of different amount of load. Also, the deformation level changes for 
different portions of the reflector surface. For pretension loads of $0.70 \mathrm{~N}$ and above, the reflector membrane distortions become predominant in the overall deformation pattern that may include rigid body motion of the dish. The reflector surface deformations are between 0 to 3 millimeters, as seen in the analysis plots for catenary loads between $0.47 \mathrm{~N}$ to $2.31 \mathrm{~N}$, after discarding the rigid body displacements from the plots. While the catenary tension increased, the internal forces in the reflector membrane increased. The maximum catenary tension of $2.31 \mathrm{~N}$ was seen to be the limiting load, under the prescribed inflated pressure of $17.4 \mathrm{~Pa}$, and above that load the membranes began to wrinkle under the applied pretension loads. The membrane wrinkling was observed from deformation plots (not shown here) generated during the analysis. Figure 10 shows that the left and right regions of the antenna surface are most sensitive to increasing the catenary load uniformally, as seen by the increasing scale of the red/dark orange contour with load.

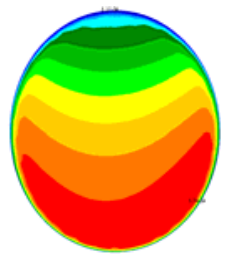

$0.47 \mathrm{~N}$

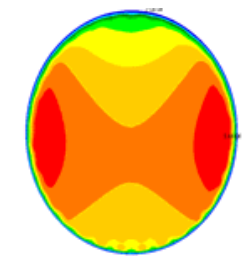

$0.70 \mathrm{~N}$

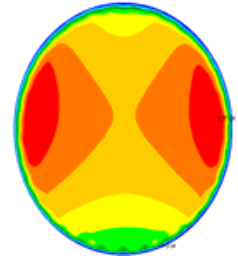

$0.93 \mathrm{~N}$

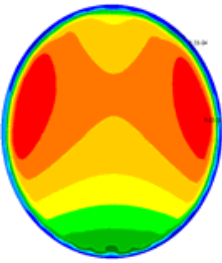

$1.39 \mathrm{~N}$

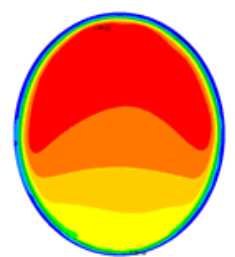

$2.31 \mathrm{~N}$

Figure 10. Deformed shape of the reflector membrane with uniform increase in pretension in the catenaries.

\section{Surface Deformation Variation with Internal Pressure and Distribution of Pretension along Reflector Edge}

Minimization of reflector surface deformation is one of the primary focuses in any antenna structural design. In the nonlinear analysis, a computational study was performed to see if the uneven deformation of the reflector surface can be reduced by varying the pretension loads in the catenaries that are located around reflector edge. Pretensions were changed in the analysis runs by increasing the size (radius) of the catenaries around the elliptical edge of the reflector. Figure 11 shows three cases of the catenary pretension distribution: (1) uniform load, (2) increased lateral load by $20 \%$, and (3) increased vertical load by $20 \%$. The increased lateral load case was achieved by increasing the load in 11 catenaries at the right and left edges of the dish. The increased vertical load case was achieved by increasing the load in 11 catenaries at the top and bottom edges of the dish. For the uniform load case, all the catenaries are equally loaded at $0.91 \mathrm{~N}$. Figure 11 shows the fringe plots from the resulting displacement fields for these three cases, with each color of the fringe band indicating a certain range of displacement (about $0.14 \mathrm{~mm}$ ). A bigger area of the band indicates more uniform displacement field. From these plots, it can be seen that the uniform load case has 3 fringe bands, which means a greater gradient of displacement across the surface. By increasing tension in the top and bottom edges or left and right edges, the displacement gradient is reduced as indicated by more area of one color band providing a more uniform displacement field. These cases show that the displacement field of the reflector surface can be tailored with appropriate selection of pretension load in the catenaries.

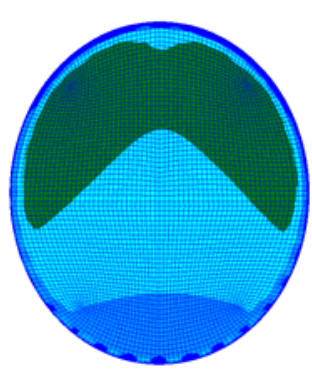

Uniform Load

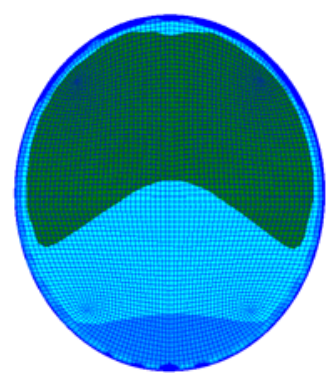

Increased Lateral Load

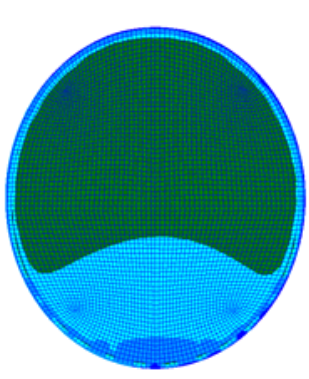

Increased Vertical Load
$1 \mathrm{~mm}$

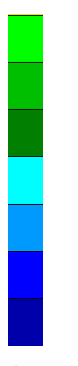

$0 \mathrm{~mm}$

Figure 11. Deformed shape of the reflector membrane for various catenary boundary loads. 
The variation of the displacement field with changes in the internal pressure under constant catenary tension $(1.38 \mathrm{~N})$ was also evaluated in the analysis computations. Figure 12 shows the reflector upper surface displacement field for various internal pressures. As can be seen from the figure, the displacement fields become more uniform with increasing internal pressure. Also, the magnitude of the displacement field reduced at higher internal pressure.

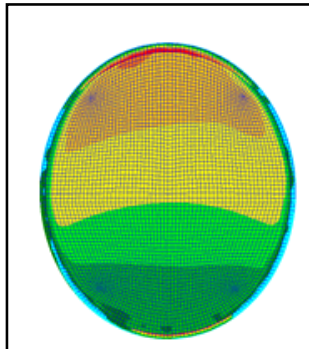

8.71 Pa

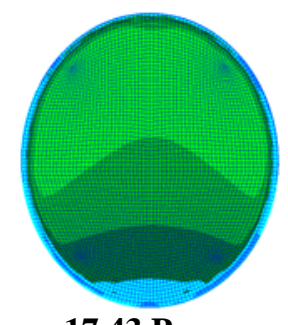

17.43 Pa

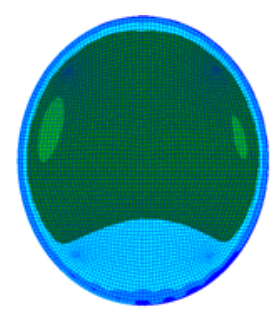

34.86 Pa

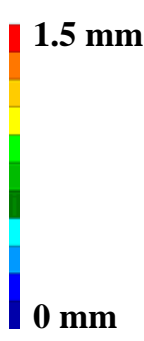

$\mathbf{m m}$

Figure 12. Reflector surface displacement field variation with different amount of internal pressure.

\section{Sensitivity to Catenary Pretension, Stiffness and Internal Pressure}

The reflector membrane surface deflections with variation in catenary pretension load, as discussed above, are extended to the case where all catenaries have a uniform pretension load. For a uniform pretension in the catenaries, the maximum deflection at a point on the upper surface is plotted against the catenary pretension in Figure 13. This plot shows that for small pretension, the dish is undergoing large deflection, primarily because of large rigid body component, and then deflection decreases with pretension. The reflector surface distortion is smallest at $0.7 \mathrm{~N}$. After about $0.97 \mathrm{~N}$ tension load, the surface displacement increased with tension until a maximum of $2.31 \mathrm{~N}$ is reached. At this higher load, the outer edge deforms considerably, and the membrane begins to wrinkle. Maximum surface deformation occurred around the outer edge of the reflector where the catenaries are connected with the reflector dish. The outer edge was stiffened to see if it reduces wrinkles in the membrane. Also, the stiffness of the catenaries was increased by an increase in cross-sectional radius of the catenaries. But the higher stiffness at the edge brought about a higher concentration of load in the outer strip, which resulted in higher deformations at the reflector edge. Next, the variation of reflector surface deflections, at a longitudinal cross-section of the reflector dish, from changes in the internal pressure with gravity load was analyzed and plotted in Figure 14. As the internal pressure is increased the dish expanded into larger cross-sectional size. The bottom surface deflection is larger than the top surface because the gravity load adds to the inflation pressure load. The sensitivities of the deflection at two points - one on the top and another on the bottom point of the cross-section - with respect to internal pressure in the reflector dish are shown in Figure 14, and in these cases a nearly constant pretension in the catenaries was maintained.

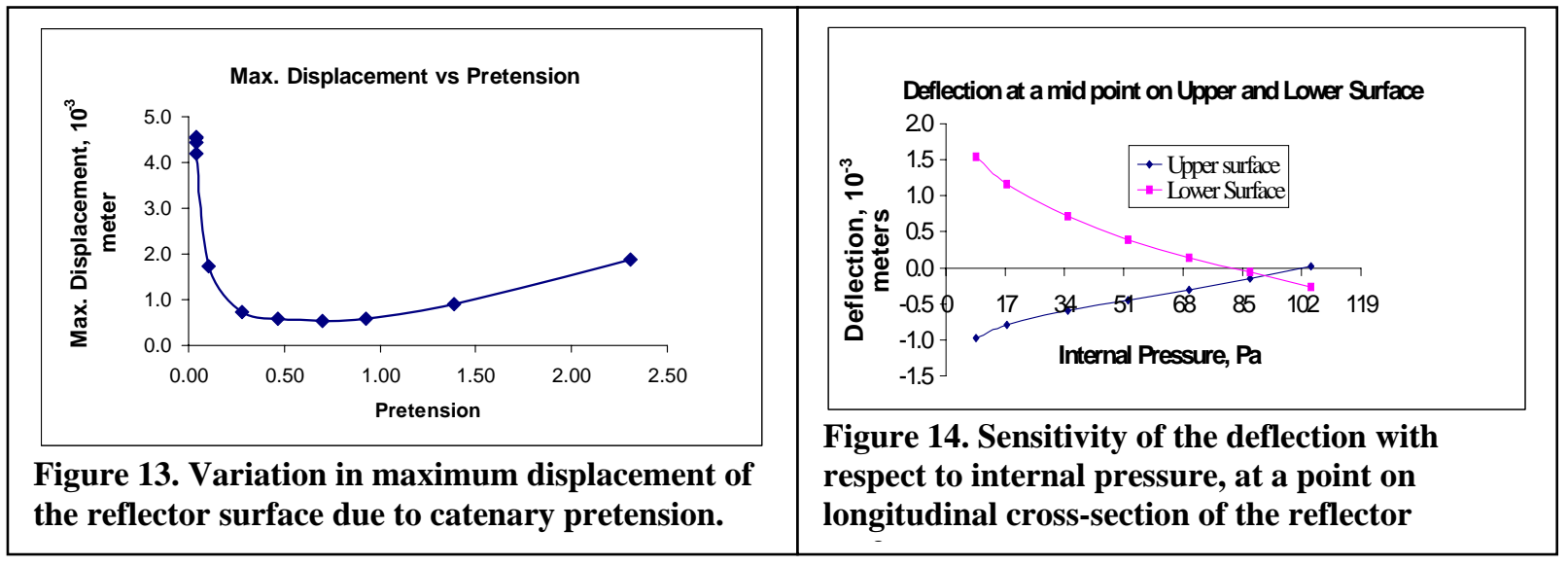




\section{Post-Test Static Analysis and Comparison with Test Measurements}

Static analysis was performed with a new set of parameters to reflect those used in the recent test. Internal pressure, catenary pretension, and membrane modulus were among the several parameters that were changed for this analysis. The internal pressure of $17.4 \mathrm{~Pa}$ used previously was changed to $14 \mathrm{~Pa}$. The previous analysis was based on gravity pointing down normal to the antenna surface, where as in the test, the antenna was mounted vertically on the oval frame for easier measurements. In the post-test static analysis, the gravitational load applied was changed to a direction pointing down along the plane of the dish in the Y-direction. The resulting static deformation of the membrane under the internal pressure of $14 \mathrm{~Pa}$ along with gravity load is shown in the Figure 15. An enlarged screen plot (not shown) of the deformation field

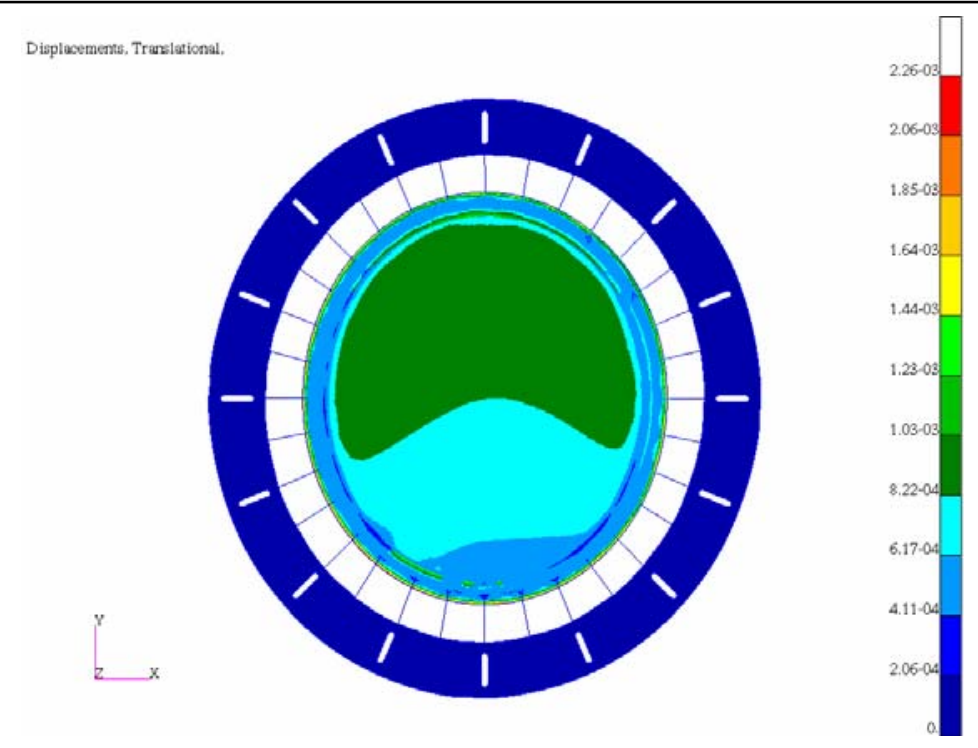

Figure 15. Static Deformation with gravity in Y-direction.

indicated that the dish has sagged in the direction of gravity, and showed a relatively smaller deformation in the top thinner section of the dish. The maximum deformation in the center region of the dish was found to be less than 2 $\mathrm{mm}$. The analysis results (see fringe pattern) show that the thinner section (top region) of the parabolic dish exhibit greater deformation than at thicker section (bottom region) of the dish.

Figure 16 shows a comparison of the static deformation from structural analysis results and test measurements along a cross-section of the upper surface of the dish. Both analysis and test points, have nearly the same curvature. Analysis points nearly follow the curvature completely up to the edges, whereas the test points flatten at the edges. In the test, edges of the membrane are not getting inflated and are some what wrinkled in the outer portion of the membrane on the right edge because of repairs.

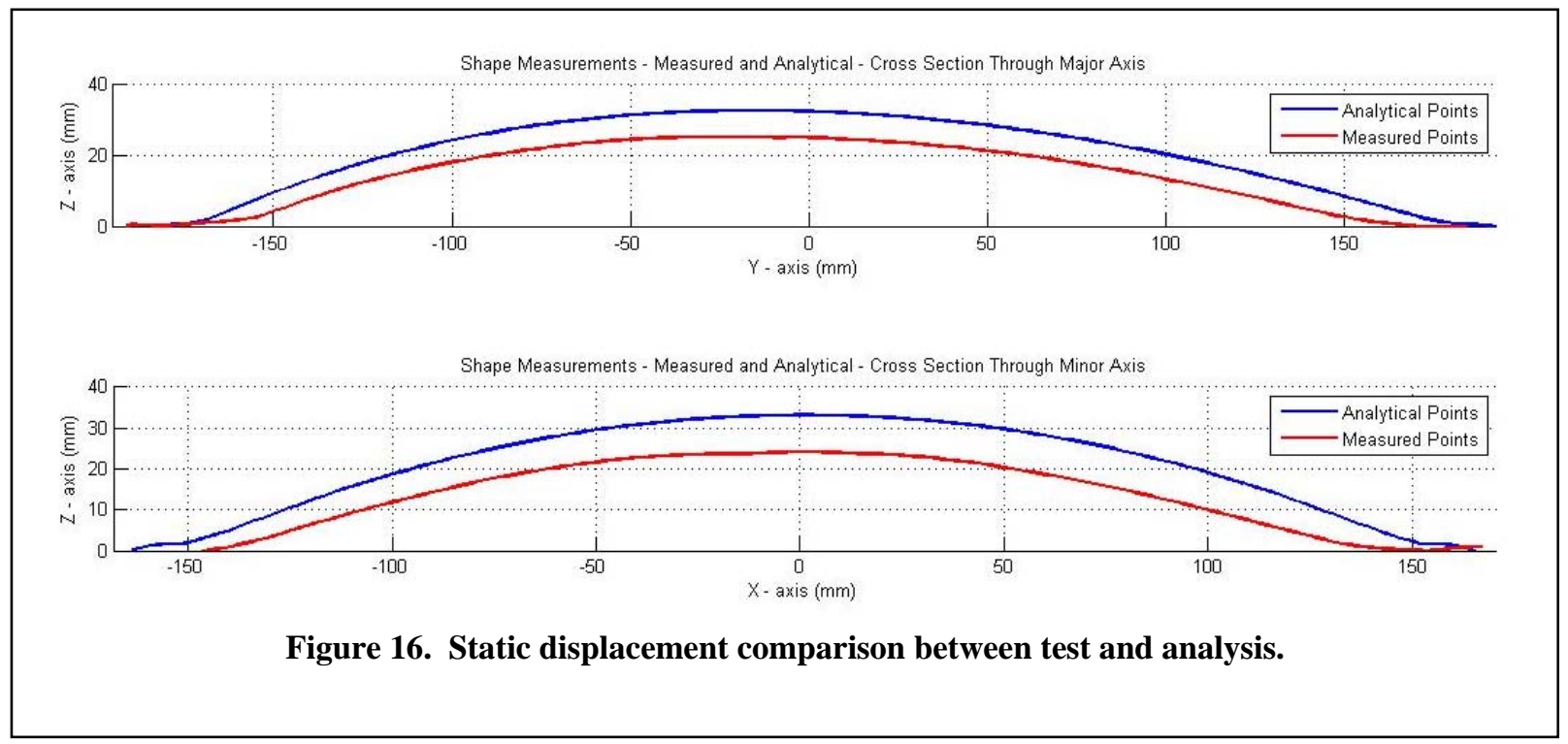




\section{Normal Mode Analysis}

\section{Catenary Flex Modes and Frame Modes}

Normal mode analysis was performed to predict the frequency characteristics of the finite element model of the reflector dish antenna. The updated stiffness matrix evaluated at the last iteration of the nonlinear static analysis and the mass matrix evaluated from the material mass density were used in the eigen-solution computation of the natural frequencies of the structure. The membrane dish has a very small mass, of the order of 4 grams, as compared with the structural mass of the oval frame, which is about $1.3 \mathrm{~kg}$. The basic low frequency modes of the reflector dish from the initial analysis are shown in the Figure 17. The rigid body modes of the dish, indicated by the dish edge being displaced as shown in the figure, arise from flexible motion of the catenaries. The figure shows the catenaries stretching in different patterns around the oval frame. A few of the rigid body motions are (1) sagging motion in the direction of gravity at $32.61 \mathrm{~Hz}$, (2) fore and aft, and lateral motion along an axis of the elliptic plane-form of the dish at 37.15 and $38.31 \mathrm{~Hz}$, (3) torsion motion in plane of the dish at $39.50 \mathrm{~Hz}$, and (4) sideway motion in the plane of the dish at $39.79 \mathrm{~Hz}$. Other combinations of these basic modes of the reflector dish were also seen in the analysis. These modes occurred in the range of frequencies up to $100 \mathrm{~Hz}$, with no significant deformation of the reflector membrane. In addition, a $47 \mathrm{~Hz}$ oval frame mode also appeared in between these low frequency modes, because of the large mass of the frame, and slotted sections within it, causing greater flexibility for frame motion.

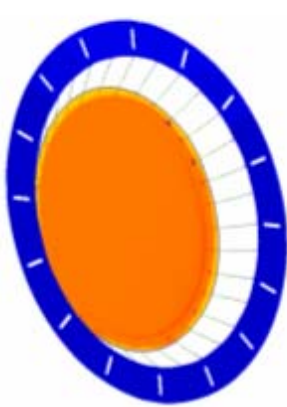

$32.61 \mathrm{~Hz}$

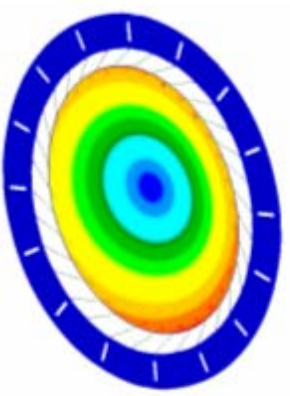

$39.50 \mathrm{~Hz}$

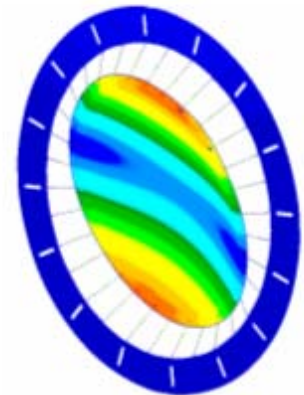

$37.13 \mathrm{~Hz}$

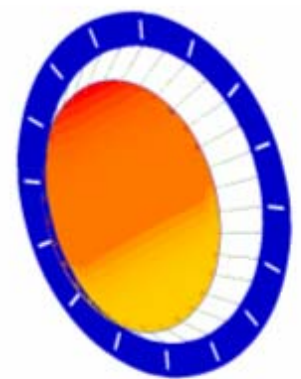

$39.79 \mathrm{~Hz}$

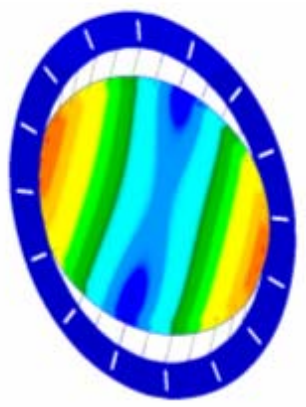

$38.31 \mathrm{~Hz}$

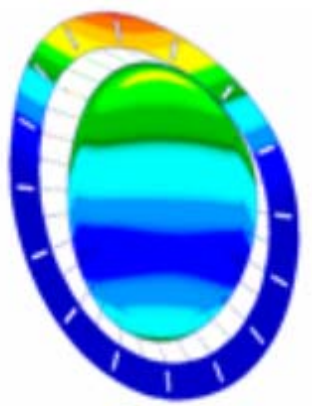

$47.61 \mathrm{~Hz}$

Figure 17. Catenary Flex Modes and Frame Modes 


\section{Outer Edge/Ring Modes and Membrane Modes}

In the frequency range of $70 \mathrm{~Hz}$ to $100 \mathrm{~Hz}$, the outer edge/ring modes of the antenna were predominant, along with some bending motion of the reflector membrane. At the lower end of this range of frequencies, the outer edge/ring was undergoing large motion, because of its relatively lower stiffness compared to the pressure stiffened membrane dish. Animation of the time varying mode shapes showed that the outer ring was undergoing cyclical out of plane motion around the circumferential edge of the reflector. As seen from Figure 18, the number of cycles (or half waves) in the edge motion increase with increasing natural frequencies of these modes. As many as 10 or more half waves were seen at higher frequencies. In these modes, the reflector membrane deforms in the vicinity of the outer edge, where significant motion occurs. A combination of outer ring mode and first bending mode of the reflector occurred at $67.93 \mathrm{~Hz}$ and $68.83 \mathrm{~Hz}$, which is shown in the Figure 23 in section 4 (post test comparison). In these two cases of membrane bending, the surface motion fall on an axis that is tilted with respect to major axis of ellipse. This is because the outer ring mode and bending mode of the reflector are coupled with the catenary flex modes. In these two bending modes, two pairs of the reflector membrane segments are bending in an orthogonal pattern with respect to each other. In the next mode at $73.72 \mathrm{~Hz}$, three pairs of membrane segments are bending accompanied by cyclical outer ring motion.

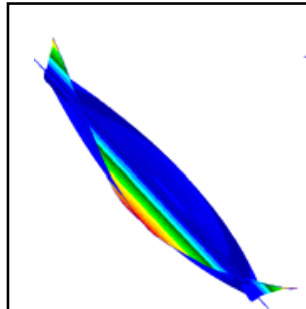

$67.93 \mathrm{~Hz}$

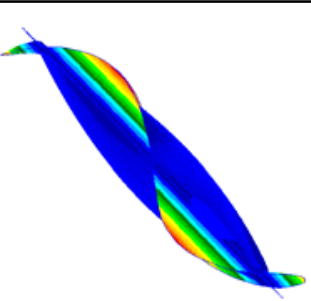

$73.72 \mathrm{~Hz}$

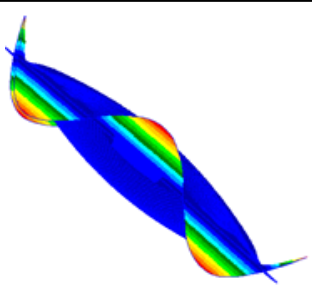

$81.72 \mathrm{~Hz}$

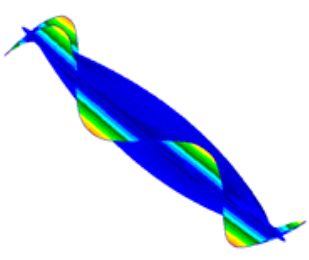

89.67 Hz

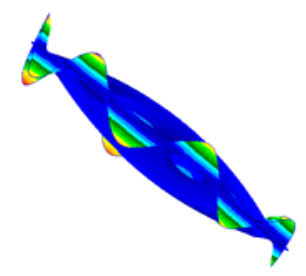

$107.26 \mathrm{~Hz}$

Figure 18. Circumferential and cyclical modes of the dish outer-edge and membrane.

\section{Sensitivity of Frequencies with Pretension and Internal Pressure}

Figure 19 shows the antenna natural frequency variation with pretension loads. A constant internal pressure of $17.4 \mathrm{~Pa}$, and a $1 \mathrm{~g}$ gravity load normal to dish was used in the computation. As seen from the figure, the natural frequencies of the basic modes increased with pretension in the catenaries. The stiffening effect of the pretension load on the natural frequencies was found to be quite significant in the analysis for frequencies up to $100 \mathrm{~Hz}$. At higher frequencies, there were many closely spaced modes and the effects of pretension load on those modes were not clearly distinguishable. Next, the effect of internal pressure on the mode shapes was also made. The internal pressure was changed in steps from $8 \mathrm{~Pa}$ to $100 \mathrm{~Pa}$, with constant pretension. The frequencies of the modes at lower frequencies $(0-100 \mathrm{~Hz})$ did not change much with increasing internal pressure because they are dominate edge/ring modes.

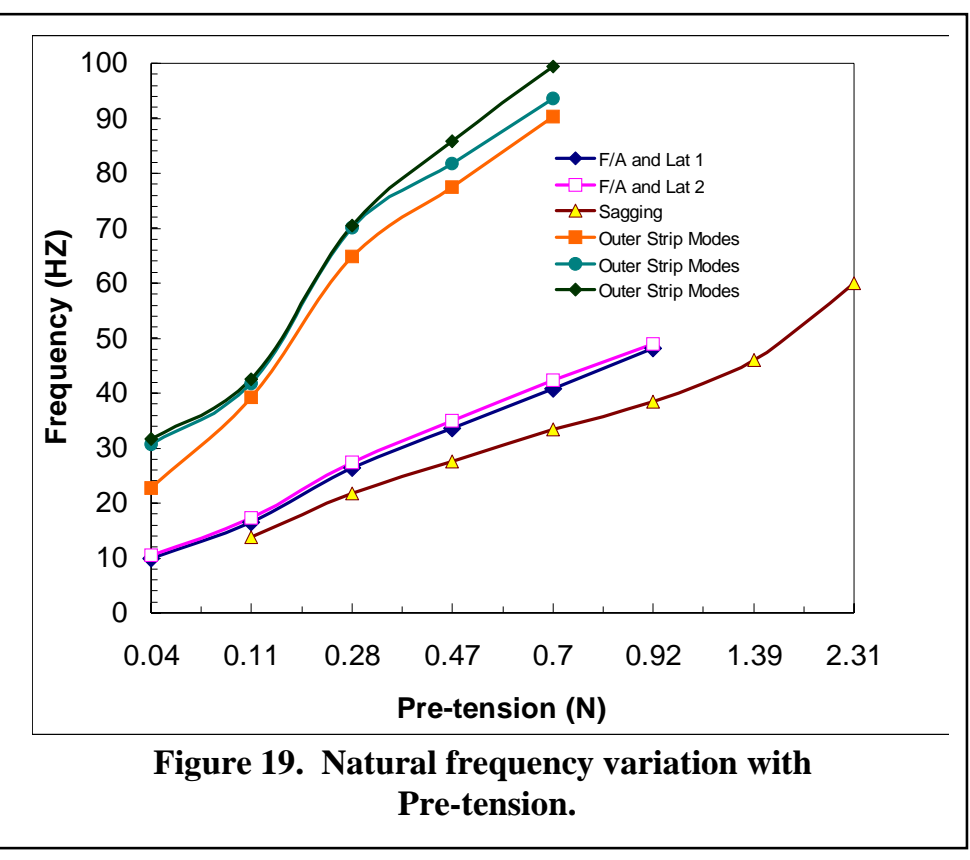




\section{Post-test Normal mode Analysis and comparison with test measurements}

The normal modes of the dish antenna were recomputed with conditions that match those of test to enable comparisons to be made between test results and analysis predicted frequencies and modes shapes of the antenna. The internal pressure was set to $14 \mathrm{~Pa}$, and several other parameters including stiffness modulus of catenaries and membranes, and catenary pretension were changed to bring the analysis as close as possible to the test conditions for predicting the normal modes of the antenna. The antenna dish rigid body modes identified from the structural analysis and test are shown in Figure 20. The upper reflector surface motions are compared here. In the sagging mode the membrane dish moves out-of-plane like a rigid body, because of the stretching motion of the catenaries. The frequencies of the sagging mode from test and analysis agree very well, which indicates that the overall stiffness and mass modeling are in good agreement. The fore and aft motion and lateral motion from test and analysis are nearly the same in frequency and type of motion. In contrast with the test modes, the fore and aft mode and lateral modes from the analysis results appear to be tilted about an axis of the elliptical plan form. However the fore and aft, and lateral motions plotted in the analysis appear orthogonal to each other. These modes occur about a tilted axis for two reasons - (1) the membrane modes are coupled with catenary flex modes, and (2) an offset in the center of gravity of the dish about the reference axis located at the center of the elliptical dish. Also, the principal inertias of the dish were different. The torsion and side modes described earlier (in section 1) are not compared here because these modes were not measured in the test as it would have require the measurement of in-plane motion of the dish (vibrometer configured to measure out-of-plane motion only).

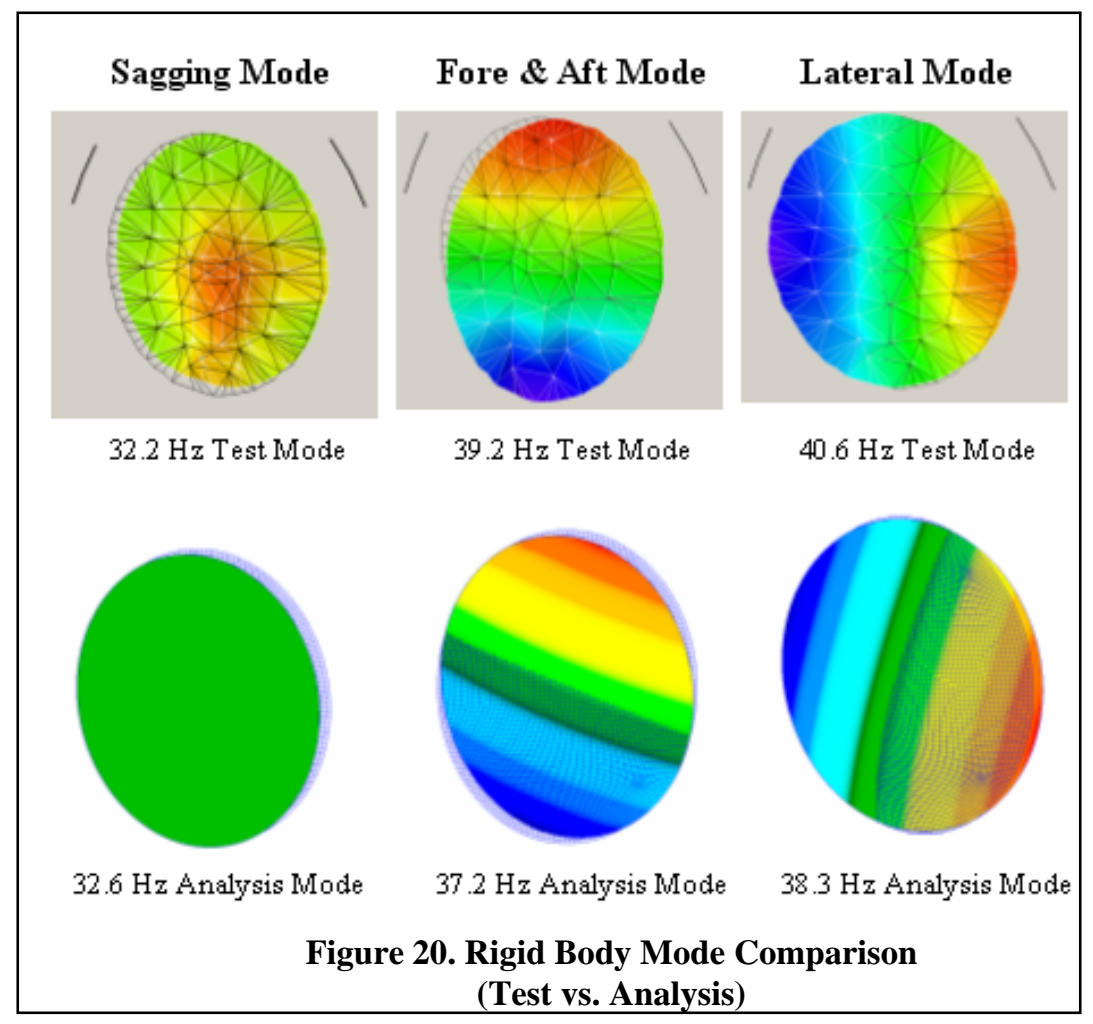

The test results had shown two lower order support frame modes in which the support frame pivots about the bolted attachment points, as shown in Figure 21. These modes were not represented in the analysis, and are believed to be due to a non-linearity involving the bolted attach points. However, the first support frame flex mode was identified and shown to match well in shape and frequency as shown in Figure 22. This mode involves the support frame flexing out-of-plane near the top section of the test article with the dish following its motion. 


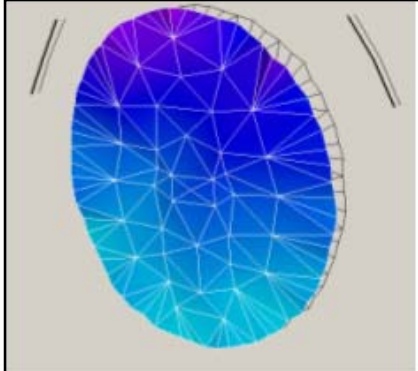

$21.6 \mathrm{~Hz}$ Test Mode

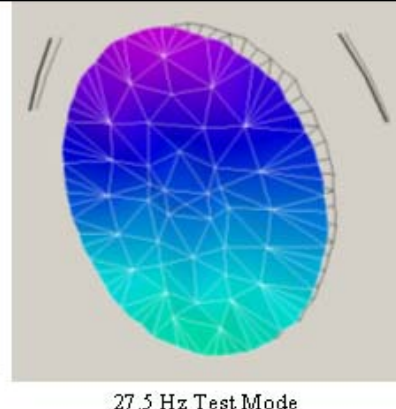

$27.5 \mathrm{~Hz}$ Test Mode

Figure 21. Support Frame Pivoting Modes (Test Modes Only)

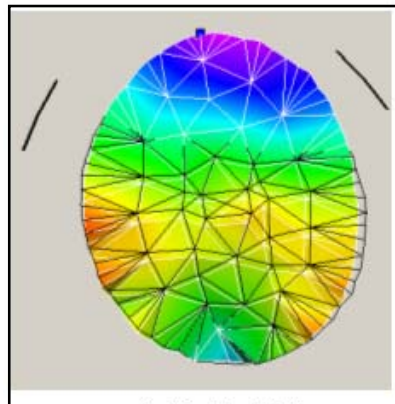

48.4 Hz Test Mode

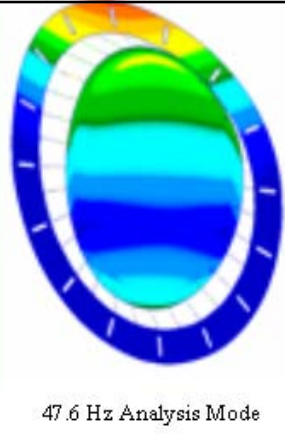

Figure 22. Support Frame Flex Mode (Test vs. Analysis)

At frequencies of $67.9 \mathrm{~Hz}$ and $68.8 \mathrm{~Hz}$, the membrane bending is seen in the analysis mode shapes in Figure 23. The membrane bending is coupled with catenary motion and also with outer edge motion. Again, the modes are tilted for the same reason as with the fore and aft and lateral modes. Test measurement depicts membrane bending at $53 \mathrm{~Hz}, 56 \mathrm{~Hz}$ and $61 \mathrm{~Hz}$ and shows similar tilt of axis of motion at $53 \mathrm{~Hz}$, and $56 \mathrm{~Hz}$. These membrane bending modes consist of bending about two orthogonal axes, and the relative motion about these axis are unsymmetrical as discussed in the previous section (blue area goes up, cyan area goes down).

The analysis membrane mode at $73.7 \mathrm{~Hz}$ has bending about three axes and this membrane bending mode is coupled with outer edge ring modes. Similarly, membrane bending motion about three axes was seen in the test result plotted at $68 \mathrm{~Hz}$. This preliminary comparison of analysis and test mode shapes brings out the complexity of modal characteristics of the inflated off-axis parabolic dish mounted on flexible catenary supports. Further evaluation of these mode shapes of analysis and tests are necessary to pinpoint the precise modes for detailed correlation and further model refinement.

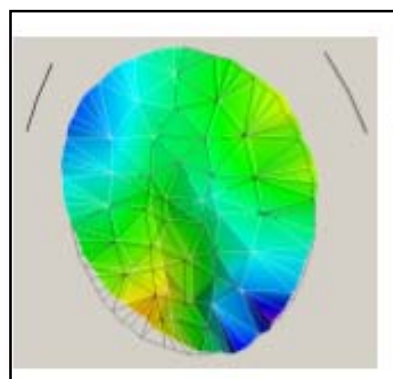

$56 \mathrm{~Hz}$ Test Mode

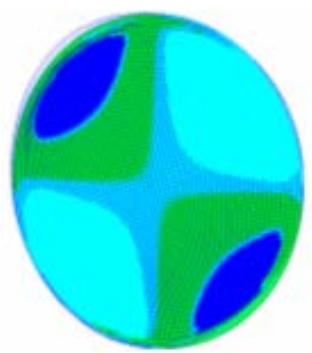

$67.9 \mathrm{~Hz}$ Analysis Mode

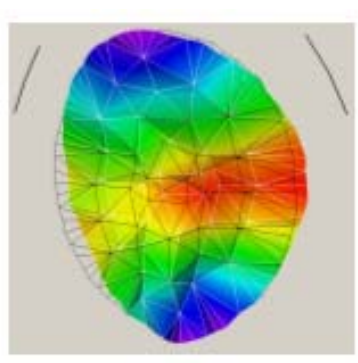

$53 \mathrm{~Hz}$ Test Mode
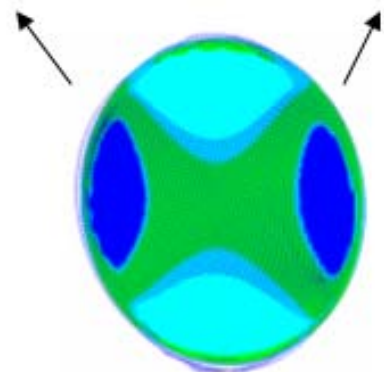

$68.8 \mathrm{~Hz}$ Analysis Mode

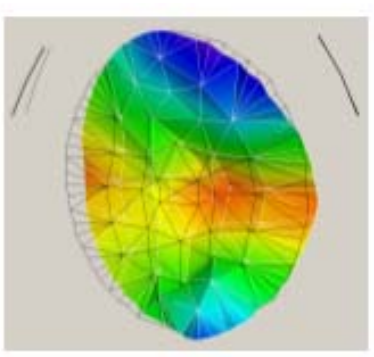

$61 \mathrm{~Hz}$ Test Mode

Figure 23. Edge/Ring and Dish Membrane Mode Comparison (Test vs. Analysis)

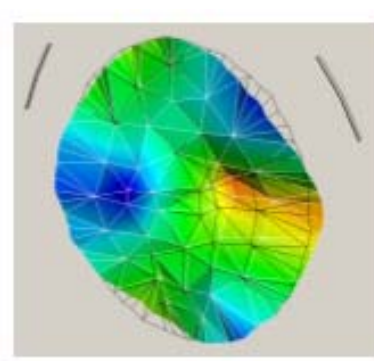

$68 \mathrm{~Hz}$ Test Mode

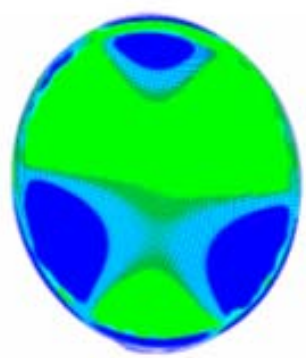

$73.7 \mathrm{~Hz}$ Analysis Mode 


\section{Concluding Remarks}

A 0.3 meter inflatable parabolic dish antenna was successfully tested for its RF characteristics and shown to have RF performance comparable to that of a conventional rigid reflector and is reasonably well matched to the analytical model predictions. A "shear" metal coating was also investigated and shown to produce comparable RF performance characteristics to the conventional coating, although at reduced weight and reduced potential for surface distortion due to wrinkles from packaging. A nonlinear static and structural dynamics computational analysis of the antenna concept was performed by developing a finite element model. The structural analysis of the antenna dish concept identified salient characteristics of the static and normal mode responses for the $1 \mathrm{~g}$ ground condition for various values of internal pressure and pretension loads in the catenaries. The outer edge/strip of the reflector dish was found to have a significant effect on the reflector surface deformations. Appropriate distribution of the pretension loads in the catenaries was shown to provide a basis to alleviate undesirable distortion of the reflector surface. Tests for antenna surface static shape and modal dynamics were completed and compared with analysis to evaluate the model accuracy. The model was shown to have similar curvature in surface shape to the test results along the centerline of the antenna surface for its major and minor axis. The model also was adjusted slightly to show the rigid body and low order flex modes match reasonably well (with some differences due in part to test article repair work), although further model refinement would be required for a detailed test-analysis correlation. Thus, it is expected that with further model refinement, simulations can be completed with the model to determine antenna performance for various mission scenarios and aid in developing the antenna concept to satisfy specific mission requirements.

\section{Acknowledgments}

The work described in this paper was funded by the Antenna Technology Program, which is managed by NASA's Space Operations Mission Directorate in Washington, D.C., and implemented by the Antenna Technology Office at Glenn Research Center in Cleveland, Ohio.

\section{References}

1. Anderson, L. J., Groth.,L.H.,"Reflector Surface Deviations in Large Parabolic Antennas," IEEE Transaction on Antennas and Propagation, March , 1962.

2. Milliken, S. A., "The development of high-gain deployable antenna for communication satellites," AIAA 66-306, AIAA Communication Satellite System Conference, Washington D.C., May 1966.

3. Rusch, W. V. T., "The current state of the reflector antenna art," IEEE Transactions on Antennas and Propagation, Vol. AP-32, No.4, April, 1984.

4. Archer, J.S., "High Performance Parabolic Antenna Reflectors, J. of Spacecraft,” Vol. 17, No. 1, 1978.

5. Guastaferro, A., "A Technology Program for Large Space System", AIAA paper 79-0921, AIAA conference, 1979.

6. Card, M. F., Boyer, W. J., "Large Space Structures," Fantasies and Facts, AIAA paper 80-0674, AIAA Conference 1980.

7. Hedgepeth, J. M., "Critical Requirements for the Design of Large Space Structures," NASA Contractor report -3484, Nov, 1981.

8. Friese, G. J., Bilyeu, G. D., Thomas, M., "Initial '80s Development of Inflated Antennas," L'GARDE Inc, NASA contractor report 166060, Jan. 1983.

9. Benton, B., " Thermal Control of Large Spacecraft Antenna Reflectors," AIAA-84-1777, AIAA 19th Thermophysics Conference, Colorado, 1984. 
10. Campbell, T. G., Bailey, J. P., Belvin, K. W., "The development of the 15-meter hoop column deployable antenna system with structural and electromagnetic performance results,” AIAA 86-0667, 1986.

11. Reaves, M. C., Belvin, K. W, and Bailey, J. P. ,"Finite-Element-Analysis Model and Preliminary Ground Testing of Controls-Structures Interaction Evolutionary Model Reflector,” NASA TM - 4293, May 1992.

12. Hedgepeth, J. M., "Interaction Between An Inflated Lenticular Reflection and Its Rim Support,” AIAA95-1510-CP, AIAA conference, 1995.

13. Palisoc, A. L. and Huang, Y., "Design Tool For Inflatable Space Structures," AIAA-97-1378, AIAA conference, 1997.

14. Greschik, G., Palisoc, A., Cassapakis, C., Veal, G., and Mikulas, M. M., "Approximating Paraboloids with Axisymmetric Pressurized Membranes," AIAA-98-2102, AIAA Conference, 1998.

15. Engberg, R. C., Lassitor, J. O.,"Modal Survey Test of the soft 2x3 meter off-axis inflatable concentrator,” AIAA-2000-1639, AIAA Conference, 2000.

16. Moore, J., and McGee, J., "Design Optimization of Thin Film Solar Concentrators Using Non-Linear Deflection Modeling,” AIAA-01-1422, AIAA conference, 2001.

17. Pappa, R. S., Jones, T. W., Black, J. T., Walford, A., Robson, S., Shortis, M. R., "Photogrammetry Methodology Development for Gossamer Spacecraft Structures," $43^{\text {rd }}$ AIAA Conference, Denver, CO, AIAA-2002-1375, 2002.

18. Gierow P.A., Paxton, J. P., Cost, T. L. , Hawk, C. W., "Material Property Effects on a Thin-Film Concentrator,” Journal of Spacecrafts and Rockets, Vol.32, No.4, July 1995.

19. Moore, J. D., Bishop, J., "Evaluation of Catenary Suspension for Reducing Shape Errors In Inflated Solar Concentrators,” AIAA-98-1985, AIAA conference, 1998.

20. Pearson, J. C., Giewrow, P. A., Lester, D., "Near Term In-space Demonstration of an Inflatable Concentrator," AIAA-99-1073, AIAA Conference, 1999.

21. Pappa, R. S., Lassiter, J. O., Ross, B. P., "Structural Dynamics Experimental Activities in Ultra-light weight and Inflatable Space Structures,” 42 ${ }^{\text {nd }}$ AIAA conference Seattle, WA, AIAA-2001-1263, 2001.

22. Gaspar, J. S., Mann, T., Behun, V., Wilkie, W. K., Pappa, R., "Development of Modal Test Techniques for Validation of a Solar Sail Design,” $45^{\text {th }}$ AIAA conference, Palm Springs, CA, AIAA-2004-1665, 2004.

23. Paxton, J., Hawk., C., "Material Property Effects on a Thin Film Solar Concentrator for Solar Thermal Propulsion,” AIAA-94-3029, AIAA Conference, 1994.

24. Veal, G., Freeland, R., "In-step Inflatable Antenna Description,” AIAA conference, 1995.

25. Willey, C. E., Schulze, R. E., Bakulic, R. S., Skullney, W. E., "A Hybrid Inflatable Dish Antenna System for Spacecraft," AIAA-2001-1258, 42nd AIAA SDM conference, 2001.

26. Lin, J. K., Sapna, G. H., Scorborough, S. E., Lopez, B. C., "Advanced Precipitation Radar Antenna Singly Curved Parabolic Antenna Reflector Development," AIAA-2003-1651, 44th AIAA SDM Conference, 2003.

27. Pearson, J. C., Unroe, M. R., "Precision Tooling for Membrane Concentrators,” AIAA-2003-5174," 39th AIAA SDM Joint Propulsion Conference, 2003. 
28. Belvin, K. W., "Ultra-light weight Structures Technology for Space Solar Power," SCTM, TIM, Sept. 2002.

29. Belvin, W. K., "Advances in Structures for Large Space Systems," AIAA-2004-5898, Space 2004 Conference and Exhibit, San Diego,VA conference, 2004.

30. MSC/NASTRAN verision 2004, McNeal Schwindler Corp, CA. 